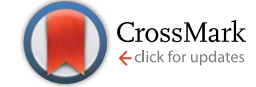

Cite this: RSC Adv., 2017, 7, 15020

Received 31st January 2017

Accepted 23rd February 2017

DOI: 10.1039/c7ra01293d

rsc.li/rsc-advances

\title{
Morphology control and large piezoresponse of hydrothermally synthesized lead-free piezoelectric $\left(\mathrm{Bi}_{0.5} \mathrm{Na}_{0.5}\right) \mathrm{TiO}_{3}$ nanofibres
}

\author{
Mohammad Bagher Ghasemian, ${ }^{a}$ Qianru Lin, ${ }^{a}$ Esmaeil Adabifiroozjaei, ${ }^{a}$ Feifei Wang, ${ }^{\text {b }}$ \\ Dewei Chu ${ }^{a}$ and Danyang Wang*a
}

\begin{abstract}
Lead-free piezoelectric bismuth sodium titanate (BNT) nanostructures were synthesised using a lowtemperature hydrothermal technique. It is found that the phase and morphology of the products are strongly dependent on the composition and concentration of the precursors, as well as the processing conditions. Through optimising the synthesis parameters, well-crystallized BNT nanofibers with 150$200 \mathrm{~nm}$ diameters and $\sim 5 \mu \mathrm{m}$ length were obtained. The BNT fibres show a pure perovskite phase with (011) orientation along the length direction. A piezoelectric constant of $d_{33}=\sim 15 \mathrm{pm} \mathrm{V}^{-1}$ in the diameter direction was observed for these BNT nanofibers.
\end{abstract}

\section{Introduction}

$\left(\mathrm{Bi}_{1 / 2} \mathrm{Na}_{1 / 2}\right) \mathrm{TiO}_{3}$ (BNT), one of the most promising lead-free piezoelectric materials was discovered in 1960 by Smolensky et al. ${ }^{1}$ A-Site complex perovskite BNT has been recognised as a leading lead-free candidate owing to its marked remanent polarization and piezoelectric coefficients, and highlighted by several research reviews. ${ }^{2-6}$ BNT-based materials have exhibited great potential for application in piezoelectric and pyroelectric devices. ${ }^{7}$ On the other hand, strong dependence of ferroelectric properties on size, structure and morphology has attracted much focus for controllable preparation of BNT nanostructures such as nanospheres, nanocubes and nanofibers. ${ }^{8}$ It has been reported that different precursors and morphologies have a significant effect on energy transition and mass of piezoelectric material after the sintering process which consequently affects the electrical properties and density of sintered piezoelectric materials. ${ }^{9,10}$ For example, sintered BNT nanofibers have higher piezoelectric constant $\left(d_{33}\right)$, planar electromechanical coupling factor $\left(k_{\mathrm{p}}\right)$ and remnant polarization $\left(P_{\mathrm{r}}\right)$ than sintered BNT nanocubes. In contrast, sintered BNT nanocubes have higher mechanical quality factor $\left(Q_{\mathrm{m}}\right)$ than that of nanofiber counterparts. ${ }^{9}$ It is also reported that crystal morphology of the BNT nanostructures, as a template, controls the grain growth and density of ceramics. Ceramics sintered from BNT nanofibers have a large grain size which facilitates domain switching and subsequently results in a significant improvement of piezoelectric and ferroelectric properties. ${ }^{9}$

${ }^{a}$ School of Materials Science and Engineering, The University of New South Wales, Sydney, NSW 2052, Australia. E-mail: dy.wang@unsw.edu.au

${ }^{b}$ Key Laboratory of Optoelectronic Material and Device, Department of Physics, Shanghai Normal University, Shanghai, 200234, China
The nanostructured materials present fascinating and applicable properties because of quantum size and specific shape effects. Particularly, one-dimensional (1D) lead-free ferroelectric materials including nanofibers, nanotubes and nanoribbons are greatly desirable owing to their high surface to volume ratio, exceptional properties in energy harvesting, photocatalysis, electromechanical device and ferroelectric memories. ${ }^{11}$ The hydrothermal synthesis is a technique presenting remarkable advantages for fabrication of onedimensional nanostructures. It offers controllable synthesis conditions and a cost-effective and low-temperature $\left(\sim 200{ }^{\circ} \mathrm{C}\right)$ route without the need of substrate that promotes easy fabrication. ${ }^{12}$ The hydrothermal synthesis provides many unique advantages which are not met by other synthetic techniques, such as direct precipitation of crystalline materials from solutions, high purity, controllable rate and homogeneity of nucleation, aging and growth, controllable size and morphology of crystals. In particular, low processing temperature can prevent undesirable changes in stoichiometry when compounds contain volatile elements such as Bi and alkali elements in many lead-free piezoelectrics. Recently, hydrothermal method was used in making BNT nanostructures with different size and shape. ${ }^{13-19}$ Lencka et al. ${ }^{13}$ was the first to synthesise BNT nanospheres and their diameters can be effectively tuned through controlling the $\mathrm{pH}$ values of precursor solutions. ${ }^{15}$ The monosized BNT nanospheres can be converted into uniform cubes when using higher mineralizer concentration. ${ }^{\mathbf{1 4 , 1 8}}$ By increasing the treatment temperature or $\mathrm{NaOH}$ concentration, nanowhiskers of BNT were resulted. ${ }^{17}$ It is also suggested that growth of BNT nanowires can be promoted by increasing the ratio of titanium to bismuth $(\mathrm{Ti} / \mathrm{Bi}=2){ }^{20}$ Also, other similar $1 \mathrm{D}$ perovskite materials such as acicular $\mathrm{BaTiO}_{3}$ nanostructures have been developed by controlling morphology through 
Table 1 Different applied precursors and controllable factors in synthesising BNT

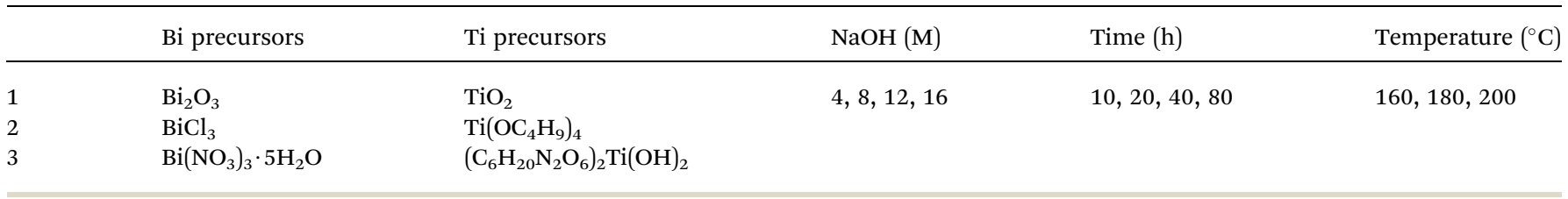

changing the growth period and phase transition of the coprecipitated amorphous phase. ${ }^{21}$

In this work, BNT nanofibers were synthesised using a facile hydrothermal technique. The effects of hydrothermal treatment time, temperature and chemicals' concentration on the morphology of BNT nanostructures were investigated. Structural and piezoelectric properties of the as-grown nanofibers were also characterised.

\section{Experimental}

The hydrothermal synthesis of BNT nanostructures started with analytical grade chemicals. Different Bi and Ti precursors were tested in order to find out the optimal combination for fabricating pure BNT phase. $\mathrm{NaOH}$ was used as both sodium source and mineralizer to control the size and morphology of the BNT nanostructures. Table 1 shows different conditions in hydrothermal synthesis of BNT with various combinations of precursors. Firstly, different combinations of Bi and Ti precursors (molar ratio of $1: 2$ ) were mixed in distilled water. Various amounts of $\mathrm{NaOH}$ were then introduced into the solution, which was stirred for one hour before transferring to a $50 \mathrm{ml}$ autoclave. The autoclave was held in an oven at different temperatures and for different periods for hydrothermal treatment. It was naturally cooled down to room temperature after the completion of hydrothermal synthesis. As-grown products were filtered and washed to natural $\mathrm{pH}$ with distilled water before drying at $110{ }^{\circ} \mathrm{C}$.

The phase structure of obtained materials was investigated by X-ray diffraction (XRD Philips X'Pert pro MPD, $\mathrm{Cu}-\mathrm{K} \alpha$ radiation, $\lambda=1.54 \AA$ ). The morphology of the synthesised BNT nanostructures was imaged by a scanning electron microscopy (SEM, Nova NanoSEM230/450). High resolution transmission electron microscopy (HRTEM, CM200, FEI) images and selected area electron diffraction (SAED) patterns were used to study the crystal size, shape and lattice structure of products. A Raman spectrometer (Reinshaw inVia) with an Ar-ion laser excitation source ( $514 \mathrm{~nm}$; continuous mode) was used to further confirm the structures of BNT nanoparticles at room temperature in $180^{\circ}$ backscattering geometry. Piezoelectric responses were examined by piezoelectric force microscope (PFM, Asylum Research).

\section{Results and discussion}

Several different precursors were used as bismuth and titanium sources to find the optimal combination for synthesising the pure BNT phase. All products were synthesised at $200{ }^{\circ} \mathrm{C}$ with $16 \mathrm{M} \mathrm{NaOH}$ and Bi : Ti molar ratio of $1: 2$ for $20 \mathrm{~h}$. Fig. 1 shows
XRD patterns for the obtained BNT nanostructures from different starting chemicals. It is found a combination of $\mathrm{Bi}\left(\mathrm{NO}_{3}\right)_{3} \cdot 5 \mathrm{H}_{2} \mathrm{O}$ and $\mathrm{Ti}\left(\mathrm{OC}_{4} \mathrm{H}_{9}\right)_{4}$ or $\mathrm{BiCl}_{3}$ and $\mathrm{TiO}_{2}$ result in the pure perovskite phase under the aforementioned hydrothermal conditions.

$\mathrm{NaOH}$ plays important roles in adjusting $\mathrm{pH}$ values of the solution and providing A-site cations for the perovskite structure in the reaction process. ${ }^{13}$ The mineralizer effect of $\mathrm{NaOH}$ on the structure and morphology of BNT nanostructures was also studied through using different concentrations of $\mathrm{NaOH}(4$, 8,12 and $16 \mathrm{M}$ ). Fig. 2a demonstrates XRD patterns for hydrothermally produced $\mathrm{BNT}$ (by $\mathrm{BiCl}_{3}$ and $\mathrm{TiO}_{2}$ as precursors) under the conditions of $200{ }^{\circ} \mathrm{C}$ after $80 \mathrm{~h}$. At low $\mathrm{NaOH}$ concentration (e.g. $4 \mathrm{M}$ ), diffraction peaks of secondary phases $\left(\mathrm{Bi}_{4} \mathrm{Ti}_{3} \mathrm{O}_{12}\right.$ and $\left.\mathrm{TiO}_{2}\right)$ are superimposed on the typical perovskite pattern. The secondary phases diminish with the increase of $\mathrm{NaOH}$ concentrations i.e. 8 and $12 \mathrm{M}$, leading to a pure BNT phase with perovskite structure as evidenced by the XRD pattern in Fig. 2a. These sharp and strong peaks in XRD pattern of nanostructures produced with high $\mathrm{NaOH}$ concentrations imply a high crystallinity of BNT perovskite phase. Moreover, $\mathrm{NaOH}$ concentration has a significant impact on the morphology of BNT nanostructures. ${ }^{22}$ When concentration of $\mathrm{NaOH}$ is $12 \mathrm{M}$, the resultant morphology is predominantly nanofibers with $\sim 200 \mathrm{~nm}$ diameter and $\sim 5 \mu \mathrm{m}$ length, as shown in Fig. $2 \mathrm{~b}$.

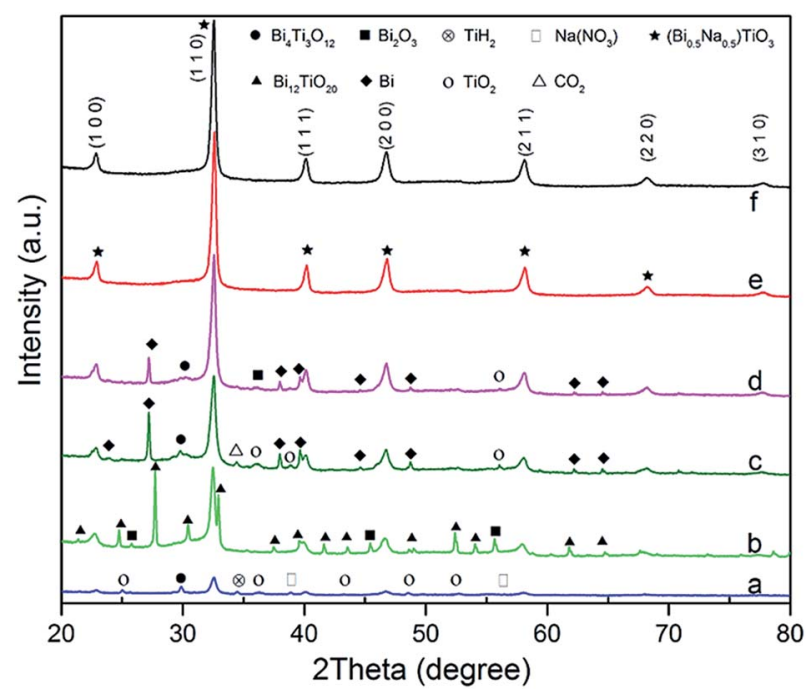

Fig. 1 XRD patterns of BNT nanostructures produced under the hydrothermal conditions of; $200^{\circ} \mathrm{C}, 20 \mathrm{~h}, \mathrm{NaOH}=16 \mathrm{M}$ by different $\mathrm{Bi}$ and Ti precursors: (a) $\mathrm{Bi}\left(\mathrm{NO}_{3}\right)_{3} \cdot 5 \mathrm{H}_{2} \mathrm{O}+\mathrm{TiO}_{2} ;$ (b) $\mathrm{Bi}_{2} \mathrm{O}_{3}+\mathrm{TiO}_{2}$; (c) $\mathrm{BiCl}_{3}$ $+\left(\mathrm{C}_{6} \mathrm{H}_{20} \mathrm{~N}_{2} \mathrm{O}_{6}\right)_{2} \mathrm{Ti}(\mathrm{OH})_{2} ;$ (d) $\mathrm{BiCl}_{3}+\mathrm{Ti}\left(\mathrm{OC}_{4} \mathrm{H}_{9}\right)_{4} ;$ (e) $\mathrm{Bi}\left(\mathrm{NO}_{3}\right)_{3} \cdot 5 \mathrm{H}_{2} \mathrm{O}+$ $\mathrm{Ti}\left(\mathrm{OC}_{4} \mathrm{H}_{9}\right)_{4}$; (f) $\mathrm{BiCl}_{3}+\mathrm{TiO}_{2}$. 

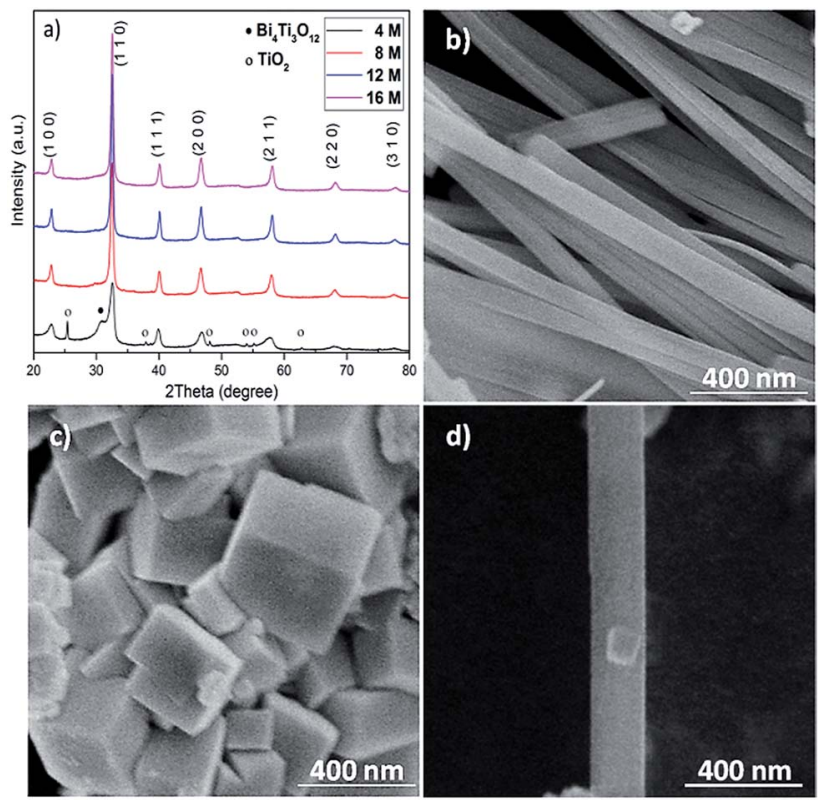

Fig. 2 XRD patterns and SEM images of hydrothermally synthesised BNT nanostructures at $200^{\circ} \mathrm{C}$ for $80 \mathrm{~h}$ with different concentrations of $\mathrm{NaOH}$. (a) XRD patterns, (b) $\mathrm{NaOH}=12 \mathrm{M}$ and (c) $\mathrm{NaOH}=16 \mathrm{M}$, (d) a typical nanocube on a nanofiber produced with $\mathrm{NaOH}=12 \mathrm{M}$.

When the concentration of $\mathrm{NaOH}$ increases to $16 \mathrm{M}$, nanocubes become the dominant morphology and their size is around $400 \mathrm{~nm}$ (Fig. 2c). Fig. 2d compares a typical BNT nanofiber and cube produced at a $\mathrm{NaOH}$ concentration of $12 \mathrm{M}$, illustrating the importance of $\mathrm{NaOH}$ concentration on the size of nanofibers and nanocubes.

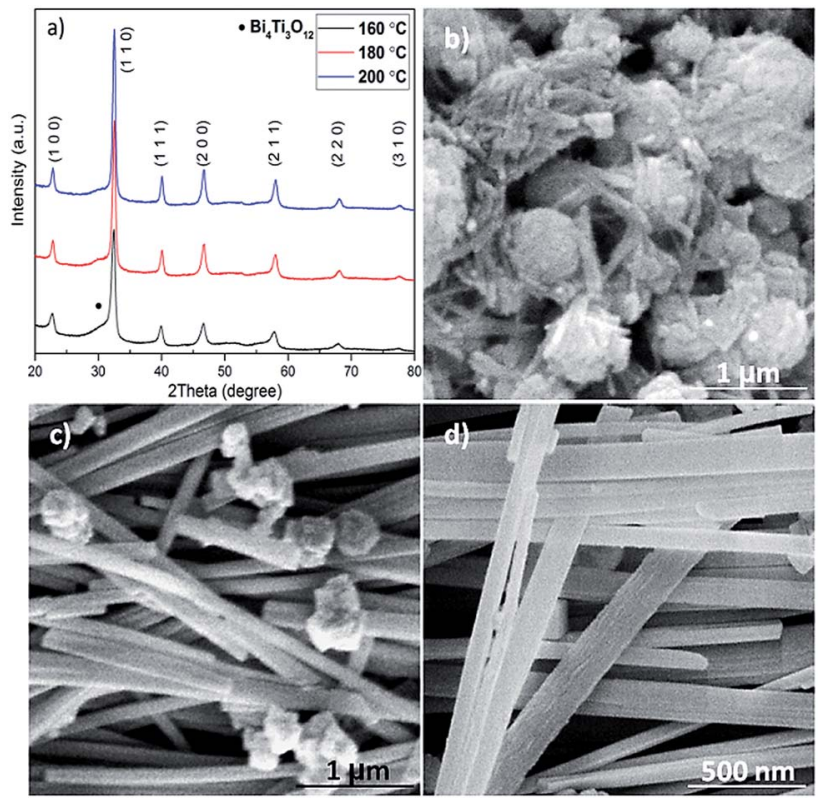

Fig. 3 XRD patterns and SEM images of hydrothermally synthesised BNT nanostructures at different temperatures with $20 \mathrm{~h}$ treatment time and $\mathrm{NaOH}=12 \mathrm{M}$. (a) XRD patterns, (b) $160^{\circ} \mathrm{C}$, (c) $180^{\circ} \mathrm{C}$ and (d) $200{ }^{\circ} \mathrm{C}$.
The BNT particles are created after the initial growth and ripening process. Throughout the hydrothermal reaction, precursors hydrolyse and initial crystals accumulate into bigger particles to reduce surface free energy. The chemical reactions occurred in the process of hydrothermal production of BNT can be expressed as: ${ }^{14,23}$

$$
\begin{aligned}
& 12 \mathrm{Bi}^{3+}+\mathrm{Ti}^{4+}+40 \mathrm{OH}^{-} \rightarrow \mathrm{Bi}_{12} \mathrm{TiO}_{20}+20 \mathrm{H}_{2} \mathrm{O} \\
& \mathrm{Bi}_{12} \mathrm{TiO}_{20}+12 \mathrm{Na}^{+} 23 \mathrm{Ti}^{4+}+104 \mathrm{OH}^{-} \rightarrow \rightarrow \\
& 24 \mathrm{Bi}_{0.5} \mathrm{Na}_{0.5} \mathrm{TiO}_{3}+52 \mathrm{H}_{2} \mathrm{O}
\end{aligned}
$$

It is shown that the increase of hydroxyl $\left(\mathrm{OH}^{-}\right)$concentration may lead to a higher growth rate. Various mechanisms for the evolution of nanocubes and nanofibers have been proposed, including dissolution-recrystallization and oriented growth. ${ }^{9}$ In the case of low $\mathrm{NaOH}$ concentration, the growth rate is different in different directions producing plates and agglomerations. The increase of mineralizer concentration might hasten the kinetics of dissolution-recrystallization process. ${ }^{22}$ In supersaturated solutions, crystallization and nucleation happen on the surface of aggregated particles, resulting in nanocubes, as shown in Fig. 2c. In supersaturated solutions with concentration of $\mathrm{NaOH}$ higher than $12 \mathrm{M}$, hydrothermal process is controlled by dissolution-crystallization mechanism and BNT particles are produced by a short and fast nucleation cycle according to Ostwald ripening phenomenon. ${ }^{24}$ Therefore, reasonably high mineralizer concentration is desirable for synthesising of uniform BNT nanocubes. On the other hand, kinetically, crystal growth also strongly depends on degree of oversaturation. ${ }^{25}$ The solution with low concentration of mineralizer is prone to the assembly of nanofibers. Due to the

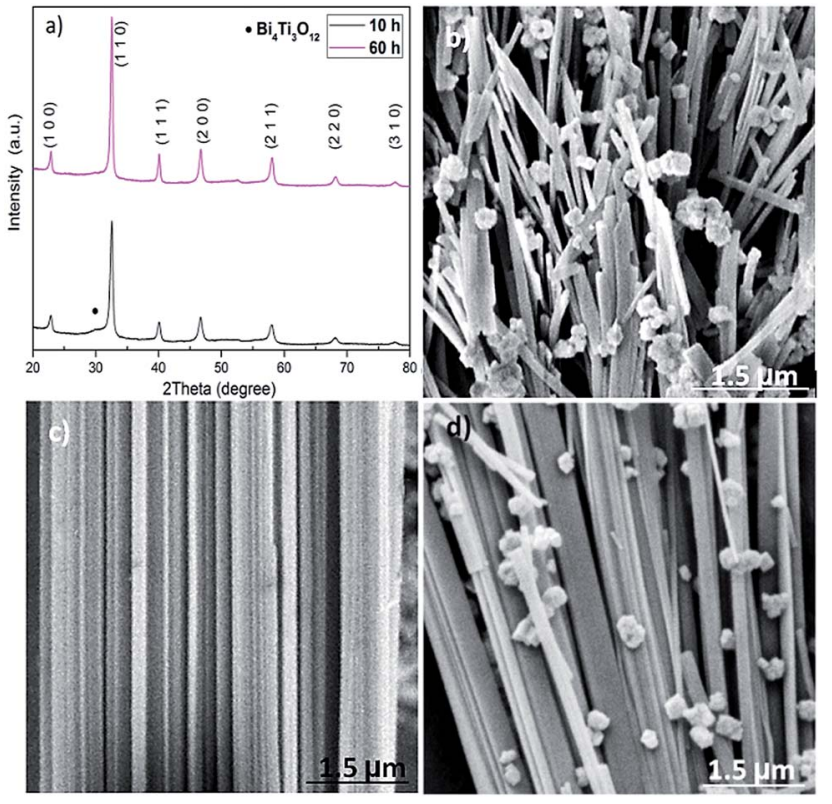

Fig. 4 XRD patterns and SEM images of BNT nanostructures synthesised at $200{ }^{\circ} \mathrm{C}$ with $\mathrm{NaOH}=12 \mathrm{M}$. (a) XRD patterns, (b) $10 \mathrm{~h}$, (c) $20 \mathrm{~h}$, (d) $60 \mathrm{~h}$ reaction time. 
Table 2 Different hydrothermal conditions and products in synthesising $\mathrm{BNT}$ by $\mathrm{BiCl}_{3}, \mathrm{TiO}_{2}$ and $\mathrm{NaOH}$ as precursors

\begin{tabular}{lllll}
\hline Temperature $\left({ }^{\circ} \mathrm{C}\right)$ & $\mathrm{NaOH}(\mathrm{M})$ & Time $(\mathrm{h})$ & Phase & Morphology \\
\hline 200 & 4 & 80 & $\mathrm{BNT}, \mathrm{Bi}_{4} \mathrm{Ti}_{3} \mathrm{O}_{12}, \mathrm{TiO}_{2}$ & - \\
200 & 8 & 80 & $\mathrm{BNT}, \mathrm{Bi}_{4} \mathrm{Ti}_{3} \mathrm{O}_{12}$ & - \\
200 & 12 & 10 & $\mathrm{BNT}, \mathrm{Bi}_{4} \mathrm{Ti}_{3} \mathrm{O}_{12}$ & Cubic, nanofiber \\
200 & 12 & 20 & $\mathrm{BNT}$ & Nanofiber \\
200 & 12 & 40 & $\mathrm{BNT}$ & Nanofiber, \\
& & & agglomeration \\
200 & 12 & 60 & $\mathrm{BNT}$ & Nanofiber, \\
& & & agglomeration \\
200 & 16 & & $\mathrm{BNT}, \mathrm{Bi}_{4} \mathrm{Ti}_{3} \mathrm{O}_{12}$ & Cubic, agglomeration \\
200 & 16 & $\mathrm{BNT}$ & Cubic \\
200 & 16 & $\mathrm{BNT}$ & Cubic \\
200 & 16 & 60 & $\mathrm{BNT}$ & Cubic, agglomeration \\
180 & 12 & 80 & $\mathrm{BNT}$ & Agglomeration, \\
& & & nanofiber \\
180 & 12 & 20 & $\mathrm{BNT}$ & Agglomeration, \\
160 & 12 & & & nanofiber \\
160 & 12 & & $\mathrm{BNT}, \mathrm{Bi}_{4} \mathrm{Ti}_{3} \mathrm{O}_{12}$ & Agglomeration \\
& & 20 & $\mathrm{BNT}, \mathrm{Bi}_{4} \mathrm{Ti}_{3} \mathrm{O}_{12}$ & Agglomeration, \\
& & & nanofiber
\end{tabular}

reduction of surface free energy, nanocubes attach one another orientally creating nanofibers.

The effect of hydrothermal treatment temperature on the structure and morphology of the produced BNT nanostructures was also studied. Fig. 3a shows XRD patterns of BNT nanostructures fabricated at 160,180 and $200{ }^{\circ} \mathrm{C}$ after 20 h hydrothermal treatment with $\mathrm{NaOH}=12 \mathrm{M}$. In the case of low temperature $\left(160{ }^{\circ} \mathrm{C}\right)$ synthesized BNT, characteristic peaks of $\mathrm{BNT}$ are clearly seen in the XRD spectrum. The broadness of the peaks suggests a rather poor crystalline quality of the BNT. Nevertheless, the appearance of a shoulder at around $2 \theta=32^{\circ}$ implies the presence of $\mathrm{Bi}_{4} \mathrm{Ti}_{3} \mathrm{O}_{12}$ secondary phase. With the increase of hydrothermal temperature to 180 and $200{ }^{\circ} \mathrm{C}$, BNT peaks become sharper and stronger, indicating a higher degree of crystallization. Particularly, almost no secondary phase is visible in the XRD pattern of BNT produced at $200{ }^{\circ} \mathrm{C}$.

The hydrothermal treatment temperature also leads to substantially different morphologies as shown in Fig. 3b-d. When treated at $160{ }^{\circ} \mathrm{C}$, BNT manifests agglomeration of nanoparticles with very fine whiskers of $\sim 50 \mathrm{~nm}$ diameter (Fig. 3b). As evidenced by Fig. 3c and d, higher treatment temperatures can effectively promote the growth of BNT nanofibers. Although a considerable amount of agglomeration is still present, fibers of $150 \mathrm{~nm}$ diameter and several microns length can be clearly seen in the SEM image (Fig. 3c). If the treatment temperature rises to $200{ }^{\circ} \mathrm{C}$, the agglomerations are almost gone and the dominant morphology is fibre with some nanocubes at local regions.

XRD patterns in Fig. 4a depict the effect of hydrothermal treatment time on the phase structure of the BNT nanostructures synthesized at $200{ }^{\circ} \mathrm{C}$ with $\mathrm{NaOH}=12 \mathrm{M}$. Weak peak of secondary phase is seen from the XRD pattern of $10 \mathrm{~h}$-treated $\mathrm{BNT}$. When the treatment time is $\geq 20 \mathrm{~h}$, the secondary phase is gone and pure perovskite phase is obtained. According to the XRD patterns, no conspicuous changes on the BNT phase structures can be detected if the treatment time is longer than $20 \mathrm{~h}$. However, the change of treatment time results in significantly different shape and morphology of the nanostructures. As shown in Fig. 4b, only the 20 h-treated samples render a nanofiber dominant morphology. All the other treatment periods lead to only a small population of fibres embedded into
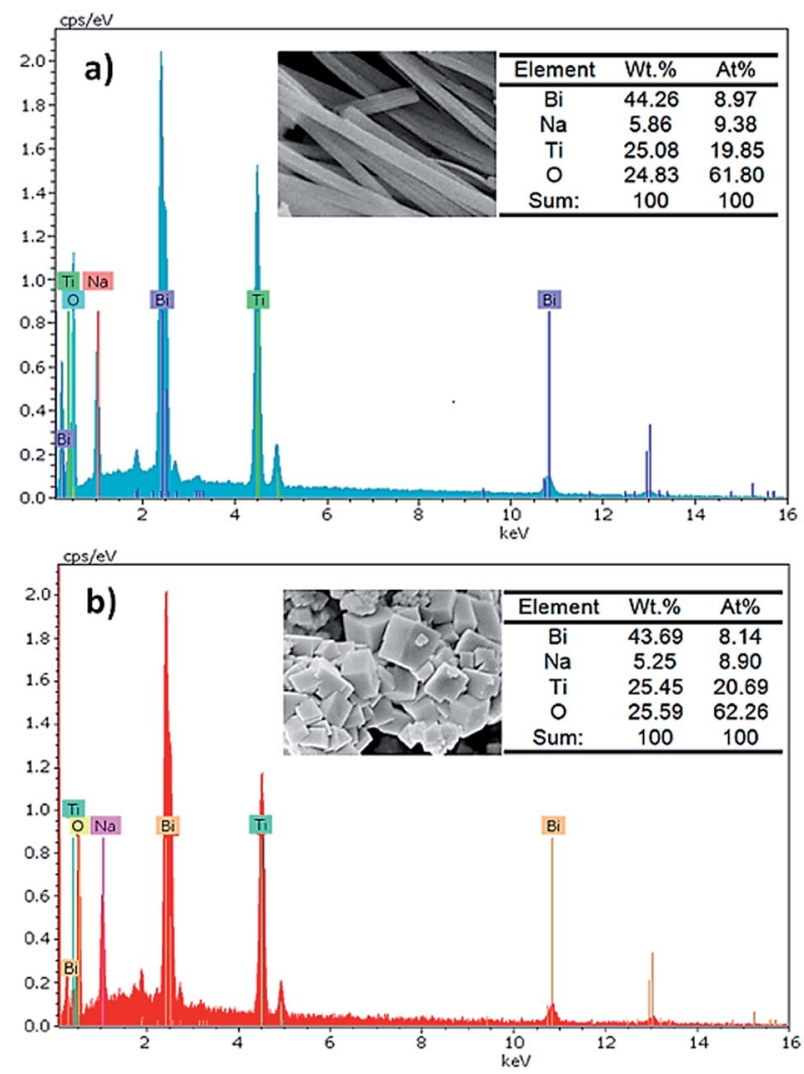

Fig. 5 EDS spectra of (a) BNT nanofibers and (b) BNT nanocubes. 
a matrix of spherical and agglomeration particles. Surprisingly, prolongation of the reaction time doesn't promote the amount of nanofibres. Therefore, the hydrothermal treatment time is critical to obtain the desired BNT morphology, i.e. nanofibres.

As discussed, the formation of BNT particles is a two-step process including dissolution and recrystallization. This suggests, by an oriented attachment process, the larger particles are produced from smaller initial nanoparticles. Then, the neighbouring nanocubes join together through a self-assembly mechanism at a planar interface and a same crystallographic direction to form BNT nanofibers. ${ }^{26}$ Thermodynamically, the elimination of high energy surfaces which leads to a significant decrease in surface free energy is the motivation for this natural oriented attachment. ${ }^{27}$ Meanwhile, for long hydrothermal treatment period, adjacent particles with different size and morphology can be self-assembled and produce bulks of cubes and nanofibers or massive agglomerations as shown in Fig. $4 \mathrm{~d}^{28}$

Table 2 summarizes the different products and morphologies of BNT nanostructures produced in various hydrothermal conditions which might be referable to other lead-free piezoelectric materials. It can be concluded that $200{ }^{\circ} \mathrm{C}, \mathrm{NaOH}=$ $12 \mathrm{M}$ and the hydrothermal treatment time of $20 \mathrm{~h}$ are the optimal conditions for synthesising BNT nanofibers whilst BNT nanocubes can be produced at $200{ }^{\circ} \mathrm{C}, \mathrm{NaOH}=16 \mathrm{M}$ and treatment period between 20 and $60 \mathrm{~h}$.

Fig. 5 shows the energy dispersive X-ray spectrometry (EDS) spectra which reveal the detailed elemental compositions in BNT nanofibers and cubes. These analyses prove that both morphologies include $\mathrm{Na}, \mathrm{Bi}$, Ti and $\mathrm{O}$ with the approximate atomic ratio of $1: 1: 2: 6$, which is in good agreement with the nominal stoichiometric ratio of BNT material. ${ }^{29}$

Fig. 6a shows the bright field TEM image of a single BNT nanofiber with a diameter about $150 \mathrm{~nm}$ synthesised under the

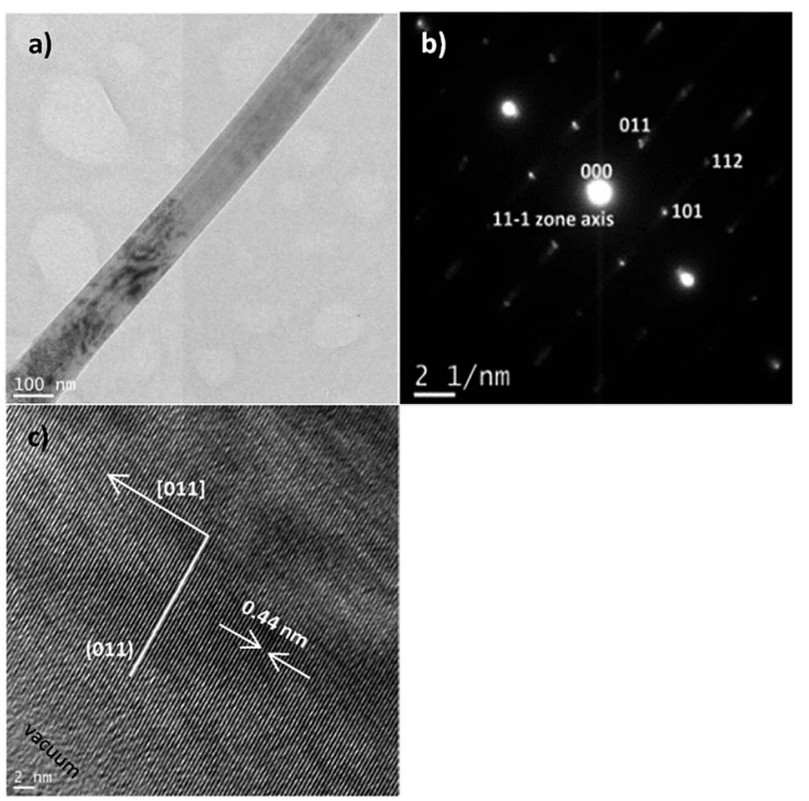

Fig. 6 (a) Bright field TEM micrograph, (b) SAED pattern and (c) HRTEM image of a BNT nanofiber.
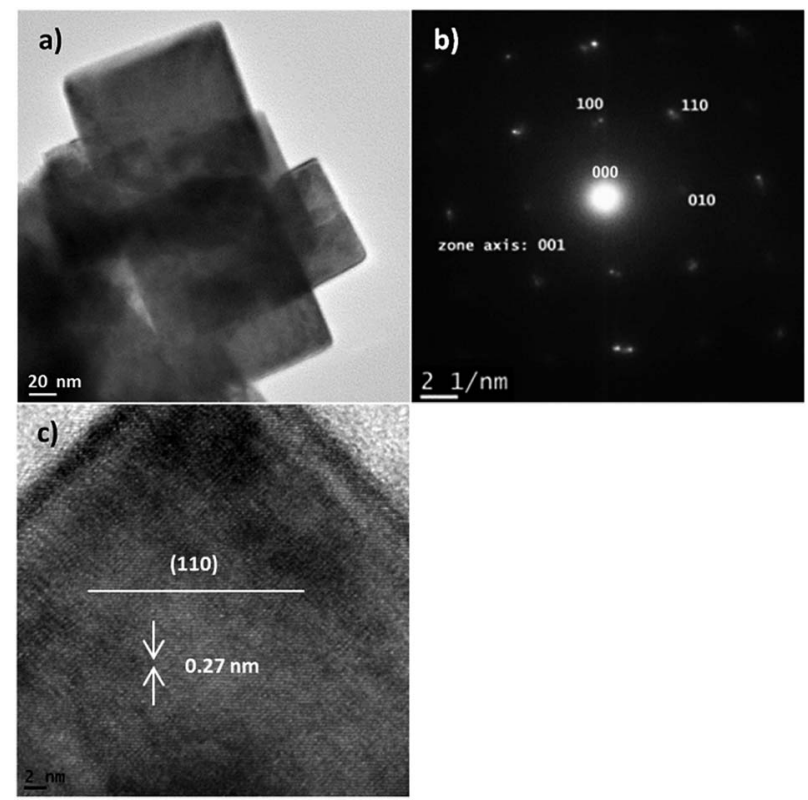

Fig. 7 (a) TEM bright field micrograph, (b) SAED pattern and (c) HRTEM image of the BNT nanocubes.

optimal conditions. Fig. $6 \mathrm{~b}$ and c show selected area electron diffraction (SEAD) pattern around the [111] zone axis and HRTEM image of a single BNT nanofiber, indicating the single crystal nature of the nanofibers. TEM characterization on the fibers showed an orthorhombic structure and the growth plane is (011) with interplanar spacing of $0.44 \mathrm{~nm}$, indicating the growth direction is [011].

Fig. 7 shows the TEM results of the BNT nanocubes, as the by-products of the nanofibres, synthesized at $200{ }^{\circ} \mathrm{C}$ for $20 \mathrm{~h}$ with $\mathrm{NaOH}$ concentration of $12 \mathrm{M}$. Nanocubes have a size range of 80-150 nm, as shown in Fig. 7a, in which a number of nanocubes overlapped. SEAD pattern (Fig. 7b) and the clear

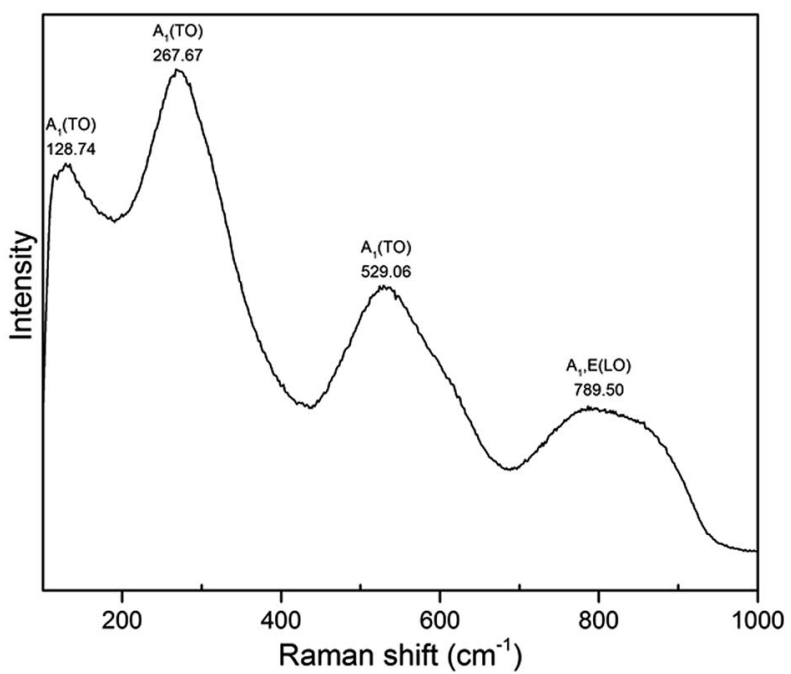

Fig. 8 Raman spectrum of BNT nanofibres synthesized at $200^{\circ} \mathrm{C}$ for $20 \mathrm{~h}$ with $\mathrm{NaOH}$ concentration of $12 \mathrm{M}$. 
lattice fringes in the HR-TEM image of a single cube (Fig. 7c) indicate that cubes are also highly crystalized. TEM characterization on the nanocubes indicates a cubic structure that the growth plane is (110) with interplanar spacing of $0.27 \mathrm{~nm}$.

Fig. 8 shows Raman spectrum of BNT nanofibres measured at room temperature. The samples were dried at $110^{\circ} \mathrm{C}$ to bake out the absorbed moisture prior to Raman measurement. Three $\mathrm{A}_{1}$ (TO) absorption bands related to perovskite structure appeared at 128, 267 and $529 \mathrm{~cm}^{-1}$ while $\mathrm{A}_{1}, \mathrm{E}(\mathrm{LO})$ band appears at $789 \mathrm{~cm}^{-1}$. Intense band at $128 \mathrm{~cm}^{-1}$ is assigned to $\mathrm{Na}-\mathrm{O}$ vibrations while bands at 267 and $529 \mathrm{~cm}^{-1}$ are associated with $\mathrm{TiO}_{6}$ octahedral vibrations. ${ }^{30-33}$

While the piezoelectric properties of many one-dimensional materials have been reported, ${ }^{34-49}$ the electrical properties of BNT nanofibers are rarely investigated. In this work, piezoresponse of BNT nanofibers was measured by PFM with Dual AC Resonance Tracking (DART) mode. The sample was prepared by dispersing BNT nanofibers in ethanol and distributing on a Ptcoated silicon wafer followed by drying at $50{ }^{\circ} \mathrm{C}$ in oven. Fig. 9a describes a schematic of the direction of a nanofiber of interest against the PFM tip. For PFM measurements, a Ti/Ir-coated silicon tip was used and a force contact of $3 \mathrm{~N} \mathrm{~m}^{-1}$ was applied. Topography, piezoresponse amplitude and piezoresponse phase images of a $200 \mathrm{~nm}$-diameter BNT nanofiber of interest are shown in Fig. 9b-d, respectively. Local piezoresponse of the BNT nanofiber was characterized by applying an AC voltage of $4 \mathrm{~V}$ between Pt bottom electrode and the conductive PFM tip under a DC voltage of $\pm 45 \mathrm{~V}$. The typical phase-voltage hysteresis
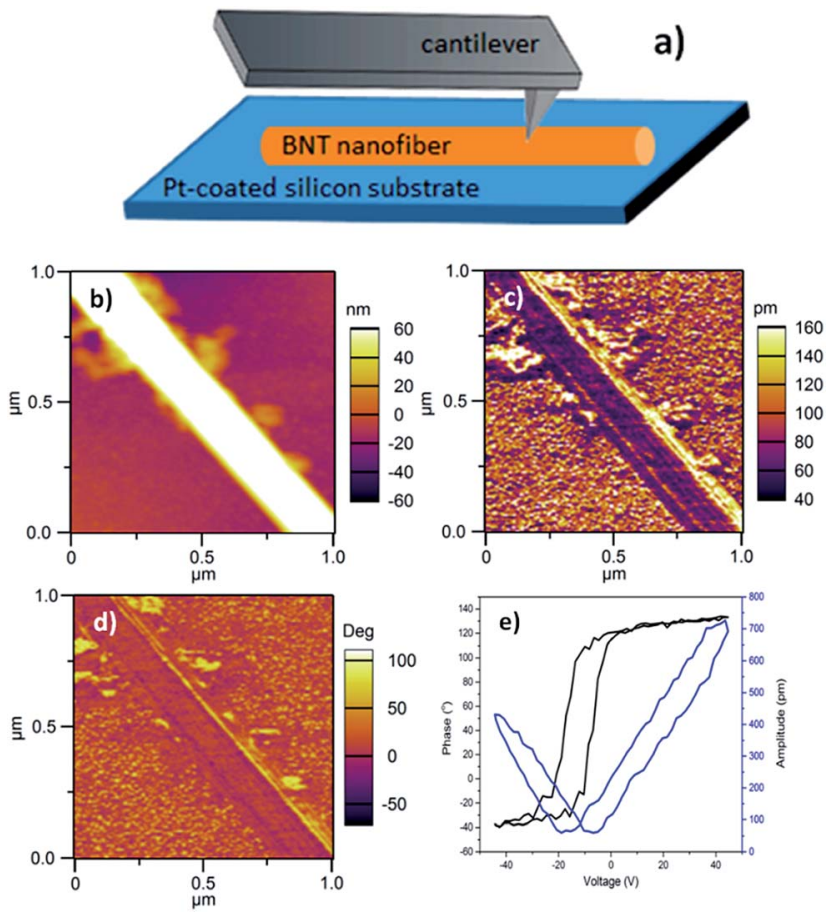

Fig. 9 PFM results of a BNT nanofibres synthesized at $200{ }^{\circ} \mathrm{C}$ for $20 \mathrm{~h}$ with $\mathrm{NaOH}$ concentration of $12 \mathrm{M}$. (a) Schematic of a nanofiber on Pt/ Si substrate for PFM measurement; (b) topography, (c) piezoresponse amplitude image, (d) piezoresponse phase image, (e) phase hysteresis and amplitude butterfly loops versus voltage.
Table 3 Piezoelectric coefficient of some hydrothermally-synthesised 1D piezoelectric nanostructures

\begin{tabular}{lll}
\hline Material & $d_{33}\left(\mathrm{pm} \mathrm{V}^{-1}\right)$ & Ref. \\
\hline $\mathrm{BNT}$ & 15 & This work \\
$\mathrm{KNbO}_{3}$ & 10.8 & 36 \\
$\mathrm{SbSI}$ & 12 & 39 \\
$\mathrm{Na}_{6}\left(\mathrm{~W}_{6} \mathrm{O}_{19}\right)\left(\mathrm{SeO}_{3}\right)_{2}$ & 12 & 42 \\
$\mathrm{NaNbO}_{3}$ & 4 & 44 \\
$\mathrm{BaTiO}_{3}$ & 31.1 & 47 \\
$\mathrm{LiNbO}_{3}$ & 25 & 48 \\
$\mathrm{KNbO}_{3}$ & 11.6 & 49
\end{tabular}

loop and amplitude-voltage butterfly loop are observed as shown in Fig. 9e. The $180^{\circ}$ piezoresponse phase reversal suggests the ferroelectric nature of the BNT nanofiber. A piezoelectric coefficient $\left(d_{33}\right)$ of $\sim 18 \mathrm{pm} \mathrm{V}^{-1}$ was estimated through measuring the slop of linear part of amplitude-voltage butterfly loop. Table 3 shows piezoelectric coefficient for some 1D piezoelectric materials synthesised with hydrothermal routes. These values indicate that our hydrothermally synthesised BNT nanofiber is highly comparable with other 1D piezoelectric materials, suggesting the potential of our BNT nanofibres for applications in nanogenerators and nanoactuators.

\section{Conclusions}

In conclusion, a morphology-optimized synthesis of BNT nanofibers has been accomplished by a simple and feasible hydrothermal method. The best combination of precursors was identified and the effect of several controllable factors on structure and morphology of BNT was investigated to increase the production of nanofibers. Effective control of the BNT morphology can be achieved through optimizing the mineralizer $(\mathrm{NaOH})$ concentration, hydrothermal treatment time and temperature. It is found that the concentration of mineralizer is the dominant factor that determines the structure and morphology of BNT nanostructures, while reaction time has a more significant impact on morphology than treatment temperature. Large volume of highly crystallized BNT nanofibres with diameter of 150-200 nm was produced under the optimized hydrothermal conditions. Good piezoelectric response of $d_{33}=\sim 18 \mathrm{pm} \mathrm{V}^{-1}$ was confirmed by the PFM measurements, implying the potential applications of our BNT nanofibres in next generation nanoelectronic devices.

\section{Acknowledgements}

This work was partially supported by the Australian Research Council Discovery Project (Grant No. DP170103514). D. Y. Wang also acknowledges the financial support of Silverstar Award, UNSW Australia (Grant number PS24402).

\section{Notes and references}

1 G. A. Smolenskii, V. A. Isupov, A. I. Agranovskaya and N. N. Krainik, Sov. Phys. Solid. State, 1961, 2, 2651. 
2 A. Safari and M. Abazari, IEEE Trans. Ultrason. Eng., 2010, 57, 2165-2176.

3 Y.-Q. Lu and Y.-X. Li, J. Adv. Dielectr., 2011, 1, 269-288.

4 I. Coondoo, N. Panwar and A. Kholkin, J. Adv. Dielectr., 2013, 3, 1330002 .

5 N. D. Quan, L. Huu Bac, D. van Thiet, V. N. Hung and D. D. Dung, Adv. Mater. Sci. Eng., 2014, 2014, 1-13.

6 D. Q. Xiao, J. G. Wu, L. Wu, J. G. Zhu, P. Yu, D. M. Lin, Y. W. Liao and Y. Sun, J. Mater. Sci., 2009, 44, 5408-5419.

7 T. Takenaka and K. Sakata, Ferroelectrics, 1989, 95, 153-156.

8 J. J. Urban, W. S. Yun, Q. Gu and H. Park, J. Am. Chem. Soc., 2002, 124, 1186-1187.

9 B. Li, M.-S. Cao, J. Liu and D.-W. Wang, J. Am. Ceram. Soc., 2016, 11, 2316-2326.

10 Y.-D. Hou, L. Hou, J.-L. Zhao, M.-K. Zhu and H. Yan, J. Electroceram., 2011, 26, 37-43.

11 Y. Zhao, R. L. Frost, W. N. Martens and H. Y. Zhu, Langmuir, 2007, 23, 9850-9859.

12 X.-Q. Fang, J.-X. Liu and V. Gupta, Nanoscale, 2013, 5, 17161726.

13 M. M. Lencka, M. Oledzka and R. E. Riman, Chem. Mater., 2000, 12, 1323-1330.

14 X. Jing, Y. Li and Q. Yin, Mater. Sci. Eng., B, 2003, 99, 506510.

15 Y. J. Ma, J. H. Cho, Y. H. Lee and B. I. Kim, Mater. Chem. Phys., 2006, 98, 5-8.

16 K. Kanie, Y. Numamoto, S. Tsukamoto, T. Sasaki, M. Nakaya, J. Tani, H. Takahashi and A. Muramatsu, Mater. Trans., 2011, 52, 1396-1401.

17 T. Lu, J. Dai, J. Tian, W. Song, X. Liu, L. Lai, H. Chu, X. Huang and X. Liu, J. Alloys Compd., 2010, 490, 232-235.

18 Y. Liu, Y. Lu and S. Dai, J. Alloys Compd., 2009, 484, 801-805.

19 J. Li, G. Wang, H. Wang, C. Tang, Y. Wang, C. Liang, W. Cai and L. Zhang, J. Mater. Chem., 2009, 19, 2253.

20 X. Ma, W. Zhang, L. Xue, S. Yin, L. Wan and Y. Yan, J. Mater. Sci., 2013, 48, 6878-6884.

21 Y. Masuda, T. Yamada and K. Koumoto, Cryst. Growth Des., 2008, 8, 169-171.

22 R. Lu, J. Yuan, H. Shi, B. Li, W. Wang, D. Wang and M. Cao, CrystEngComm, 2013, 15, 3984.

23 J. Yu, M. Zhang and M. Guo, CrystEngComm, 2011, 13, 19531958.

24 B. L. Cushing, V. L. Kolesnichenko and C. J. O'Connor, Chem. Rev., 2004, 104, 3893-3946.

25 J. Tang and A. P. Alivisatos, Nano Lett., 2006, 6, 2701-2706.

26 P. Pookmaneea, S. Phanichphanta and R. B. Heimann, CFI, Ceram. Forum Int., 2001, 78, 28-30.
27 Q. Zhang, S.-J. Liu and S.-H. Yu, J. Mater. Chem., 2009, 19, 191-207.

28 J. H. Jung, M. Lee, J. Il Hong, Y. Ding, C. Y. Chen, L. J. Chou and Z. L. Wang, ACS Nano, 2011, 5, 10041-10046.

29 X. Zhou, C. Jiang, C. Chen, H. Luo, K. Zhou and D. Zhang, CrystEngComm, 2016, 18, 1302-1310.

30 Y. Wang, G. Xu, L. Yang, Z. Ren, X. Wei, W. Weng, P. Du, G. Shen and G. Han, Ceram. Int., 2009, 35, 1657-1659.

31 M.-S. Zhang, J. F. Scott and J. A. Zvirgzds, Ferroelectr., Lett. Sect., 1986, 6, 147-152.

32 M. K. Niranjan, T. Karthik, S. Asthana, J. Pan and U. V. Waghmare, J. Appl. Phys., 2013, 113, 0-7.

33 J. Kreisel, A. M. Glazer, P. Bouvier and G. Lucazeau, Phys. Rev. B, 2001, 63, 174106.

34 Y. Q. Chen, X. J. Zheng, X. Feng, D. Z. Zhang and S. H. Dai, Phys. Status Solidi RRL, 2009, 292, 290-292.

35 Y. Q. Chen, X. J. Zheng, X. Feng, S. H. Dai and D. Z. Zhang, Mater. Res. Bull., 2010, 45, 717-721.

36 I. Shoji, T. Kondo, A. Kitamoto, M. Shirane and R. Ito, J. Opt. Soc. Am. B, 1997, 14, 2268.

37 Z. Wang, A. P. Suryavanshi and M.-F. Yu, Appl. Phys. Lett., 2006, 89, 82903.

38 X. Li, Y.-F. Lim, K. Yao, F. E. H. Tay and K. H. Seah, Chem. Mater., 2013, 25, 524-529.

39 L. Liang, X. Kang, Y. Sang and H. Liu, Adv. Sci., 2016, 3, 1-21. 40 Z. Wang, J. Hu, A. P. Suryavanshi, K. Yum and M.-F. Yu, Nano Lett., 2007, 7, 2966-2969.

41 M. Ghosh, S. Ghosh, M. Seibt, K. Y. Rao, P. Peretzki and G. Mohan Rao, CrystEngComm, 2016, 18, 622-630.

42 S. D. Nguyen and P. S. Halasyamani, Inorg. Chem., 2013, 52, 2637-2647.

43 M. Liao, X. L. Zhong, J. B. Wang, S. H. Xie and Y. C. Zhou, Appl. Phys. Lett., 2010, 96, 12904.

44 T. Y. Ke, H. A. Chen, H. S. Sheu, J. W. Yeh, H. N. Lin, C. Y. Lee and H. T. Chiu, J. Phys. Chem. C, 2008, 112, 8827-8831.

45 S. Xu, G. Poirier and N. Yao, Nano Energy, 2012, 1, 602-607. 46 D. Y. Wang, K. Li and H. L. W. Chan, Sens. Actuators, A, 2004, 114, 1-6.

47 H. Tang, Z. Zhou and H. A. Sodano, Appl. Phys. Lett., 2014, 104, 142905.

48 B. Yun, Y. Park, M. Lee, N. Lee, W. Jo, S. Lee and J. Jung, Nanoscale Res. Lett., 2014, 9, 4.

49 M.-R. Joung, I.-T. Seo, J.-S. Kim, H. Xu, G. Han, M.-G. Kang, C.-Y. Kang, S.-J. Yoon and S. Nahm, Acta Mater., 2013, 61, 3703-3708. 